\title{
A Genetic Assessment of Parentage in the Blackspot Sergeant Damselfish, Abudefduf sordidus (Pisces: Pomacentridae)
}

\author{
Lisa Kerr Lobel ${ }^{1,2, *}$, Devin M. Drown ${ }^{3}{ }^{-}$, Paul H. Barber ${ }^{4}$ and Phillip S. Lobel ${ }^{2}$ \\ 1 Department of Science, Middlesex Community College, 591 Spring Rd., Bedford, MA 01730, USA \\ 2 Department of Biology, Boston University, 5 Cummington Mall, Boston, MA 02215, USA; plobel@bu.edu \\ 3 Institute of Arctic Biology, University of Alaska Fairbanks, 902 N. Koyukuk Dr., Fairbanks, AK 99775, USA; \\ dmdrown@alaska.edu \\ 4 Department of Ecology and Evolutionary Biology, University of California, 621 Charles E. Young Dr. South, \\ Los Angeles, CA 90095, USA; paulbarber@ucla.edu \\ * Correspondence: llobel@bu.edu; Tel.: +1-781-280-3856
}

Received: 10 August 2019; Accepted: 11 October 2019; Published: 24 October 2019

\begin{abstract}
Microsatellite markers were used to investigate the reproductive behavior of the damselfish Abudefduf sordidus at Johnston Atoll, Central Pacific Ocean. Genetic results indicated that ten males maintained guardianship over their nest territories for up to nine nest cycles during a 3.5 month period. Genotypes of 1025 offspring sampled from 68 nests (composed of 129 clutches) were consistent with $95 \%$ of the offspring being sired by the guardian male. Offspring lacking paternal alleles at two or more loci were found in 19 clutches, indicating that reproductive parasitism and subsequent alloparental care occurred. Reconstructed maternal genotypes allowed the identification of a minimum of 74 different females that spawned with these ten territorial males. Males were polygynous, mating with multiple females within and between cycles. Genetic data from nests, which consisted of up to four clutches during a reproductive cycle, indicated that each clutch usually had only one maternal contributor and that different clutches each had different dams. Females displayed sequential polyandry spawning with one male within a cycle but switched males in subsequent spawning cycles. These results highlight new findings regarding male parasitic spawning, polygyny, and sequential polyandry in a marine fish with exclusive male paternal care.
\end{abstract}

Keywords: reproductive behavior; paternity; microsatellite; alloparental care; alternative reproductive tactic; polyandry; fish spawning

\section{Introduction}

It is intrinsically interesting to the study of evolution to define the reproductive patterns of species with contrasting phylogeny and ecology. Polyandry has evolved in some nesting species of birds and fishes wherein the sex roles are reversed and a female reproduces with several males, each of who raises the offspring with little or no help from the mother. How this reproductive pattern is actually expressed in living species directly relates to parental investment, sex roles, and sexual selection theory $[1,2]$. As individuals strive to increase their fitness, conflicts between the sexes may arise due to the unequal contribution of resources during reproduction and care of the offspring [3]. Theory predicts that if one sex is released from parental care duties, polygamy will increase and therefore species with exclusive parental care are predicted to have polygynous mating systems [4,5]. One hypothesis is that polygamy in both sexes of nest-tending marine fish may minimize reproductive skew and maximize genetic diversity within populations [6]. However, other factors such as resource availability, population density or distribution, as well as female choice may also play a role in determining mating systems [7]. 
The demersal spawning habits and exclusive paternal care of offspring by damselfishes have allowed their reproductive ecology to be relatively well studied among coral reef fishes [8,9]. While the focus of many damselfish studies is often on the correlates of male mating success, inferences about female behavior can also be made by quantifying the number of clutches spawned within a nest [10-17], and from direct observations of tagged females [16]. However, it is difficult to make continuous direct observations of fish spawning in the field due to a variety of factors including dive time limits, water visibility, fishes avoiding divers, and the need to determine the optimal times to be underwater for observations (e.g., dawn, dusk, night, or tidal). The territorial nature of male damselfish guarding their nests make them easy to observe, but very little is known regarding mate choice, spawning behavior, and frequency of female damselfish in this temporarily territorial species. The use of genetic methods can be utilized to quantify aspects of reproductive behavior for both sexes that are not always observable.

Molecular markers have been an important tool for the study of mating systems of fishes, often highlighting important differences between the social and genetic mating systems [17-20]. Given the diversity of fishes (34,000+ species) [21], as well as the differences in their mating systems [3,22], there are many unanswered questions that lend themselves to molecular analysis. Damselfishes are good subjects for genetic mating system analysis due to their territorial nature, cyclic reproduction, and conspicuous nesting habits that allow the collection of offspring from a large number of nests over multiple reproductive cycles.

The blackspot sergeant damselfish, Abudefduf sordidus (Forsskål, 1775), is a large (160 mm SL) benthic omnivore found throughout the Indo-west Pacific [23]. Juveniles are found in shallow tide pools while adults inhabit rocky lagoon and reef flat shorelines [24]. The reproductive biology of A. sordidus has been studied in the field [25-28]. Like other damselfishes, A. sordidus spawn in demersal nests with parental care provided exclusively by the male (Video S1). The demersal spawning site is a limited resource defended by large territorial males, with observations suggesting the same guardian male uses the same site throughout the spawning season [25]. This nesting behavior is in contrast to the majority of other reef fishes who broadcast spawn with resultant planktonic embryos and no parental care.

Nesting activity is cyclic, beginning when a male prepares the nest site (the physical location used for spawning) by biting off any encrusting material or organisms and allowing fine filamentous algae to grow. Females are attracted to the nest site by the male's bright spawning coloration, exaggerated swimming, and courtship sounds [26]. Males can receive up to five clutches of embryos per nesting cycle, usually spawned one or two days apart and laid in discrete locations in the single nest site (Figure 1). Parental care includes embryo defense, and the cleaning and fanning of the embryos to provide adequate oxygenation. For each nesting cycle, parental care ends after all clutches in the nest have hatched. Embryos hatch in five to six days depending on water temperature. Males abandon the nest site between cycles, returning a few days before the next cycle to regain possession of the same nest site and prepare it for new clutches [27]. While male reproductive output can be documented by egg presence in the nest, little is known regarding female reproductive behavior or whether reproductive parasitism occurs.

In this study, paternal and offspring genotypes were used to determine male site fidelity, paternity, and to identify maternal genotypes for a subset of individuals spawning in a population of the blackspot sergeant damselfish (Abudefduf sordidus) on a Pacific coral reef. Since the actual spawning act was rarely observed, the genetic data were used to define male and female mating patterns. Specific questions were: (1) Is male nest site fidelity supported by genetic evidence?; (2) Do some males employ parasitic reproductive tactics by sneaking fertilizations from territorial males?; (3) Are males polygynous or are multiple clutches in a nest spawned by only one female?; (4) Do females spawn multiple times within and between cycles?; and (5) Do females show nest site fidelity or are females polyandrous within and between spawning cycles? The use of microsatellite markers in this study adds to our visual observations of the social mating system of $A$. sordidus by further elucidating the mating dynamics, 
and in particular, provides previously unknown information about female reproductive ecology and mating tactics in this species.

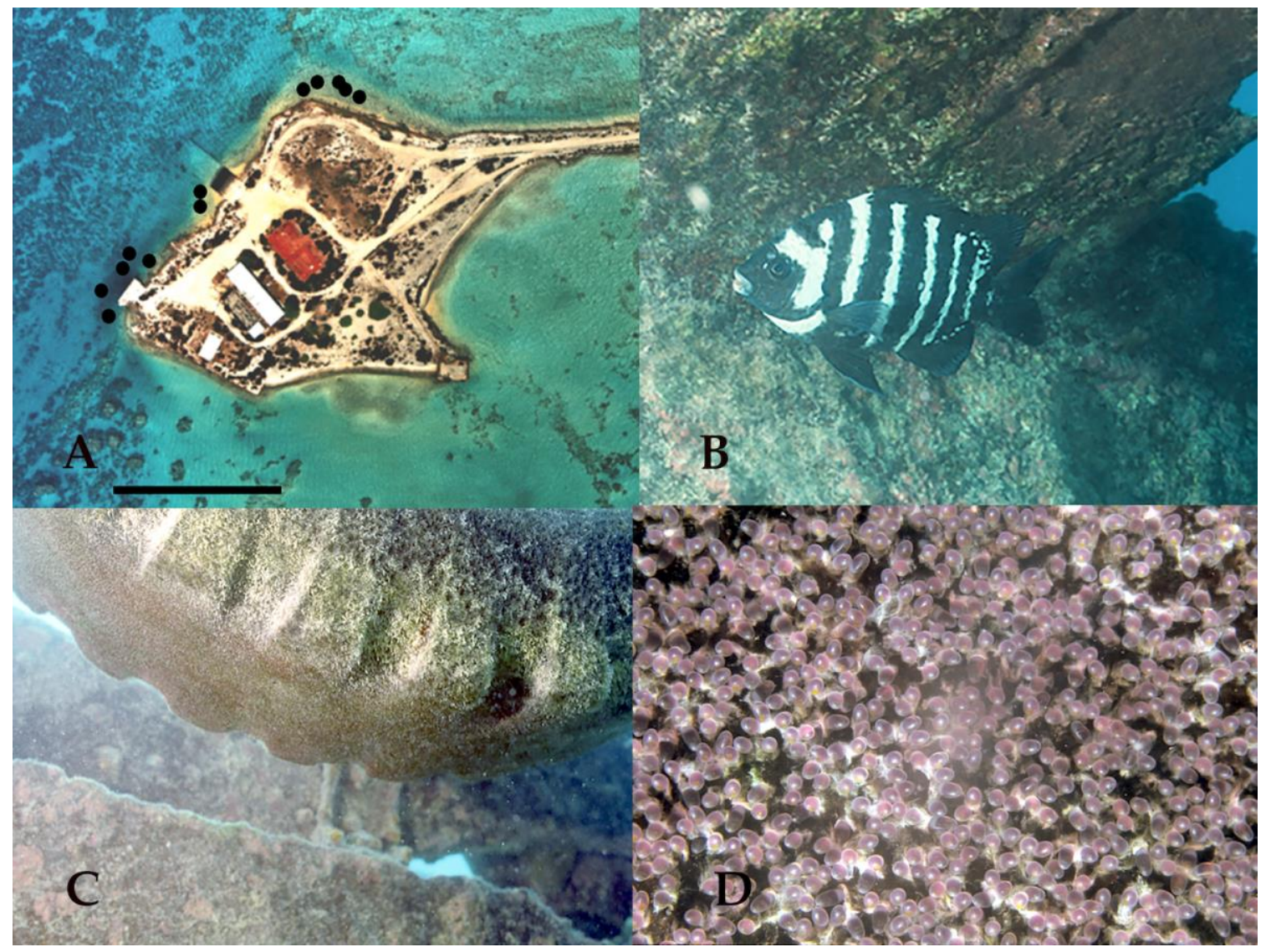

Figure 1. (A) Aerial view of the west end of Sand Island with black dots indicating nest site locations. From left to right the nest sites are K, N, Ch1, L, Pipe, H, Z, B, 1, F1, F2, and E1. Clutches in nest sites H and $\mathrm{Z}$ were spawned by the same male, as were clutches in sites $\mathrm{B}$ and 1 . The scale bar indicates $100 \mathrm{~m}$. (B) Male defending a clutch of embryos at nest site "F1". Males only adopt the high contrast black and white coloration during spawning and courtship. The pinkish area in the top right of the photo is the newly spawned clutch. (C) Nest site " $\mathrm{H}$ " located on a submerged tire. The guardian male has prepared the nest site to receive embryos. (D) Macro photograph of newly spawned embryos. Embryos are $1 \mathrm{~mm}$ in length.

\section{Results}

\subsection{Microsatellites}

The six microsatellite loci had 5-10 alleles each, resulting in single locus non-exclusion probabilities ranging from 0.496 to 0.732 (with the first parent known) and a combined multilocus non-exclusion probability of 0.054 for the first parent and 0.007 for the second parent (CERVUS 3.0.7; Tables 1 and 2). Frequencies of null alleles indicating heterozygote deficit ranged from -0.0402 to 0.0439 . This set of polymorphic loci provided sufficient power to discriminate among closely related individuals, and enabled the confirmation of paternity by a known male and the reconstruction of genetic identities for maternal assignments. 
Table 1. Microsatellite primer information.

\begin{tabular}{|c|c|c|c|}
\hline Locus & Primers & Repeat & Size Range \\
\hline \multirow{2}{*}{ D123 } & F: HEX-caacgaacaaaaggcaaacaaa & \multirow{2}{*}{$(\mathrm{TAGA})_{\mathrm{n}}$} & \multirow{2}{*}{$128-180$} \\
\hline & R: cactattaaccccagcaagacc & & \\
\hline \multirow{2}{*}{ D113 } & F: 6-FAM-caaggttaccaagcgtgaaatg & \multirow{2}{*}{$(\mathrm{TAGA})_{\mathrm{n}}$} & \multirow{2}{*}{$192-232$} \\
\hline & R: attcgtggttttccttcatcag & & \\
\hline \multirow{2}{*}{ D112 } & F: HEX-atggacaccacgctagtattac & \multirow{2}{*}{$(\mathrm{TAGA})_{\mathrm{n}}$} & \multirow{2}{*}{$141-181$} \\
\hline & R: caagttggctgaatgtctgctg & & \\
\hline \multirow{2}{*}{ D7 } & F: 6-FAM-caggaggcattagtcatcaaag & \multirow{2}{*}{$(\mathrm{TAGA})_{\mathrm{n}}$} & \multirow{2}{*}{$196-228$} \\
\hline & R: tatagcacccagtaattacaag & & \\
\hline \multirow{2}{*}{ C9 } & F: HEX-cagatgtttgatggagagatac & \multirow{2}{*}{ (CATC)n } & \multirow{2}{*}{$164-220$} \\
\hline & R: agcagaaccaaacagtccaagc & & \\
\hline \multirow{2}{*}{ D102 } & F: 6-FAM-aaatctcagcagcaaacatctc & \multirow{2}{*}{$(\mathrm{TAGA})_{\mathrm{n}}$} & \multirow{2}{*}{$272-312$} \\
\hline & R: tgtccgtcctcctcccatcaga & & \\
\hline
\end{tabular}

Table 2. Microsatellite marker polymorphism in Abudefduf sordidus, based on alelles in 74 adult females (reconstructed genotypes) and 10 adult males. Number of alleles, observed $\left(H_{\mathrm{O}}\right)$ and expected $\left(H_{\mathrm{E}}\right)$ heterozygosities, non-exclusion (NE) probabilities (under the 'one parent known' or 'two parent known' models), results of the goodness-of-fit Hardy-Weinberg (HW) equilibrium test, and null allele frequency based on heterozygote deficit are shown for each locus.

\begin{tabular}{cccccccc}
\hline \multirow{2}{*}{ Locus } & $\begin{array}{c}\text { Number } \\
\text { of Alleles }\end{array}$ & \multirow{2}{*}{$\mathbf{H}_{\mathbf{O}}$} & $\mathbf{H}_{\mathbf{E}}$ & $\mathbf{N E}$ & $\mathbf{N E}$ & \multirow{2}{*}{$\mathbf{H W}$} & \multirow{2}{*}{$\mathbf{F}$ (Null) } \\
\cline { 5 - 6 } & & & & $\mathbf{1 - P} \mathbf{a}$ & $\mathbf{2 - P}$ & & \\
\hline D123- & 10 & 0.845 & 0.797 & 0.579 & 0.402 & $*$ & -0.0356 \\
D113- & 10 & 0.798 & 0.839 & 0.496 & 0.325 & NS & 0.0262 \\
D112- & 8 & 0.738 & 0.803 & 0.568 & 0.390 & NS & 0.0439 \\
D7- & 9 & 0.738 & 0.791 & 0.589 & 0.411 & NS & 0.0293 \\
C9- & 5 & 0.655 & 0.681 & 0.763 & 0.610 & NS & 0.0171 \\
D102- & 7 & 0.726 & 0.683 & 0.732 & 0.562 & NS & -0.0402 \\
Mean & 8.2 & & & $0.054^{+}$ & $0.007^{+}$ & & \\
\hline
\end{tabular}

${ }^{\text {a }}$ Non-exclusionary power based on allele frequency analysis (Cervus 3.0.7). * Significant departure from Hardy-Weinberg equilibrium detected. NS-Not significant. ${ }^{+}$Combined non-exclusionary power.

\subsection{Nesting and Spawning Activity}

A total of 140 clutches were spawned in 68 nests at the ten nest sites over 3.5 months. All of these nest sites were laid on artificial substrates consisting mostly of old military debris [27,28]. When re-establishing territories after a break between cycles, males were observed with torn and bit fins and with scrapes on their bodies, suggesting high levels of competition and physical fighting for nest sites. Reproductive output per male varied with individuals guarding from two to nine nests containing from five to 19 clutches during the 3.5 months (Table 3). The mean number of clutches per nest was $2.1(\mathrm{SD}=0.66)$. Offspring samples were genotyped in 129 of the 140 clutches. The remaining clutches could not be sampled or genetic data were not collected due to inaccessibility, cannibalized clutches, or failure to amplify. Offspring genotypes indicated that two males utilized alternate nest site locations in addition to their primary nest site location. Specifically, offspring genotypes were consistent with paternity by the male using nest site B in a neighboring nest (Site 1) containing two clutches. This male guarded 14 clutches in seven nests consecutively in site B and then switched to the alternate site (1), guarding one nest with two clutches. Additionally, offspring in nest site $Z$ were consistent with paternity by the male defending nest site $\mathrm{H}$. The male using nest sites $\mathrm{H}$ and $\mathrm{Z}$ spawned 
13 clutches in nest site $\mathrm{H}$ and six clutches in site $\mathrm{Z}$ (six and three nests respectively). However this male alternated between the two sites located on adjacent tires of a submerged jeep.

Table 3. Summary of spawning activity and parentage data. Spawning activity for each male includes the number of nest cycles and number of clutches spawned in these nests. Except for two males that used two nesting sites (bold), one guardian male was associated with each nest site. Clutches analyzed includes those for which genetic data were successfully collected. The number of clutches where reproductive parasites were detected includes only those clutches where alleles in at least one offspring did not match paternal alleles at two or more loci. The total number of offspring assigned to each guardian male is compared to the number of offspring with genotypes incompatible with the guardian male. The resulting percentage of unrelated offspring cared for by the guardian male and the number of females identified spawning with each male is reported.

\begin{tabular}{|c|c|c|c|c|c|c|c|c|}
\hline Male ID & $\begin{array}{l}\text { Nest } \\
\text { Cycles }\end{array}$ & $\begin{array}{l}\text { Clutches } \\
\text { Spawned }\end{array}$ & $\begin{array}{l}\text { Clutches } \\
\text { Analyzed }\end{array}$ & $\begin{array}{l}\text { Clutches } \\
\text { Parasitized }\end{array}$ & $\begin{array}{c}\text { Offspring } \\
\text { Sired by } \\
\text { Male }\end{array}$ & $\begin{array}{l}\text { Offspring } \\
\text { Not Sired } \\
\text { by Male }\end{array}$ & $\begin{array}{l}\text { Alloparental } \\
\text { Care }(\%)\end{array}$ & $\begin{array}{c}\text { Number of } \\
\text { Females }\end{array}$ \\
\hline F2 & 7 & 14 & 14 & 3 & 105 & 12 & 11 & 9 \\
\hline $\mathrm{N}$ & 8 & 15 & 15 & 3 & 115 & 8 & 7 & 11 \\
\hline Pipe & 2 & 4 & 4 & 0 & 27 & 0 & 0 & 4 \\
\hline E1 & 6 & 15 & 14 & 0 & 102 & 0 & 0 & 10 \\
\hline $\mathrm{B} / \mathbf{1}$ & 8 & 16 & 16 & 5 & 106 & 10 & 9 & 10 \\
\hline $\mathrm{F} 1$ & 6 & 12 & 11 & 1 & 79 & 2 & 4 & 8 \\
\hline $\mathrm{H} / \mathrm{Z}$ & 9 & 19 & 18 & 1 & 141 & 2 & 1 & $14^{*}$ \\
\hline Ch1 & 6 & 11 & 11 & 2 & 96 & 5 & 5 & 8 \\
\hline $\mathrm{K}$ & 9 & 17 & 13 & 2 & 103 & 8 & 8 & 9 \\
\hline $\mathrm{L}$ & 7 & 15 & 12 & 2 & 98 & 4 & 4 & 9 \\
\hline Total & 68 & 138 & 129 & 19 & 974 & 51 & $5^{\circledR}$ & $74^{\#}$ \\
\hline
\end{tabular}

During the 3.5 month study period, we made a total 106 dives between 0700 and $1800 \mathrm{~h}$ but only observed spawning during 15 of the 106 dives. During each spawning observation of between 10-60 min, only one male and one female were observed spawning, with no sign of intrusion from neighboring males or additional females. The spawning lasted longer than a one hour observation period.

\subsection{Genetic Paternity}

The genetic evidence taken over this one spawning season of 3.5 months indicated that males successfully return to and spawn repeatedly within the same nest sites, spawning in up to nine nest cycles (males $\mathrm{K}$ and $\mathrm{H} / \mathrm{Z}$ ).

In 110 of the total 129 clutches analyzed 974 (95.0\%) of the 1025 offspring displayed genotypes consistent with paternity by the guardian male (Table 3). There were no samples where all offspring were inconsistent with paternity by the guardian male, indicating that nest takeovers were not documented. However, reproductive parasitism via sneaking was indicated by a mixture of offspring sired by the guardian male and those by an unknown male (e.g., not one of the resident 10 males that were genotyped) or another guardian male. There were nine clutches containing a single offspring where neither allele at a single locus matched those of the guardian male, indicating a potential scoring error. Therefore, only those clutches with offspring genotypes containing mismatched alleles, or alleles inconsistent with paternity by the guardian male at two or more loci were considered as incidences of reproductive parasitism. Reproductive parasitism was observed in $19(15.5 \%)$ of the 129 clutches analyzed. Not all guardian males were subject to the same level of reproductive parasitism, as sneaked fertilizations were not detected in nests of some males, while up to five nests were parasitized for other guardian males. Within the 19 parasitized clutches, the number of offspring not sired by the guardian male ranged from 1 to 5 (mean $=2.3 ; \mathrm{SD}=1.29$ ) out of the mean of $8(\mathrm{SD}=2.6)$ 'offspring analyzed per clutch'. Overall, the ten guardian males cared for 973 out of 1025 (95\%) offspring that were in fact, 
sired by them. Conversely, guardian males provided care for an average of $5 \%$ (range $0 \%-11 \%$ ) of offspring, sired by another male that successfully sneaked fertilizations in his nest.

Colony (v. 2.0.6.5) was used to determine the number of male contributors in nests where reproductive parasites were detected, to determine if parasite genotypes could be identified and found in the nests of other guardian males. Of the nineteen clutches containing offspring not sired by the guardian male, there was evidence for the guardian male and one reproductive parasite in 13 of the clutches. The guardian male and two reproductive parasites were detected in three clutches, while one clutch contained offspring potentially sired by three parasites, and one clutch potentially containing offspring from four parasites. Definitive multilocus genotypes (prob $=1$ ) for these reproductive parasites could not be determined due to the small number of offspring sampled. For the majority of the parasitic males, the most probable genotypes as determined by Colony, did not match the 10 genotyped males except in offspring from two of the clutches. There were two offspring (Table S1: Offspring As511.05 and As511.06) detected in the parasitized clutch of male F1 that were consistent with paternity by the neighboring male F2 (prob $=0.114$ ). These were the only two males detected in this clutch with a single dam. In another clutch, the genotype of one offspring (AS222.10) in the nest of male $\mathrm{N}$ was consistent with paternity by male $\mathrm{K}$ (prob $=0.946$ ). This clutch contained evidence of up to five males spawning with one female. The numbers of parasitic males detected in the 19 samples increase the number of males spawning in the ten nests from just the 10 guardians to at least 27 males competing for opportunities to spawn in these nest sites.

\subsection{Genetic Maternity}

Genotypes for 74 females (some spawning multiple times) were identified in offspring from 90 clutches that contained no more than two maternal alleles at a single locus, which indicated that these offspring had a single dam. Repeat spawning females (12 spawned two times and 2 spawned three times) account for the difference between 90 and 74 . Overall, 90 of $116(76.7 \%)$ clutches were spawned by a single female, while 20 clutches contained offspring that were spawned by a minimum of two females, and seven clutches that contained offspring with at least three maternal contributors. The remaining 13 of the 129 clutches sampled did not have sufficient number of offspring genotypes to determine number of female contributors. In clutches containing offspring sired by parasitic males, even if the territorial male's genotype was missing in some offspring, the mother's genotype could sometimes be identified in the offspring sired by the territorial male and compared to the offspring sired by the parasite.

Female genotypes were used to assess spawning frequency, nest site fidelity and the number of females contributing to a male's nest. These data documented that $60(81.1 \%)$ of identified females spawned one time, while 12 females spawned two times and 2 females spawned three clutches during the 3.5 months study period. As female genotypes were not detected in neighboring nest sites during the same day, this suggests that individual females laid their entire clutch with a single male. In addition, females were not detected spawning multiple clutches within a single nest cycle or spawning multiple times within five days. Therefore even for females that were detected spawning multiple times during the 3.5 month period, one clutch was spawned per nesting cycle. The time interval between successive female spawnings ranged from 14 to 69 days $(M=37 ; S D=15)$.

Only one of the 14 multiple spawning females displayed some nest site fidelity, returning to spawn with the same male in a later nest cycle. This female (369) was detected spawning two times in the nest of male $\mathrm{Z}$ ( 56 days between clutches) and then spawned a third time in the nest of male $\mathrm{K}, 39$ days after the second clutch. This female's genotype (prob $=0.297$ ) was identified by Colony as the potential dam of another clutch spawned in the nest of male B, suggesting this female might have spawned four times. This clutch was spawned two weeks after the first clutch spawned in $Z$ and would mean that this female spawned with $Z$, potentially switched to $B$, switched back to $Z$ and then spawned with K. Overall, nest site fidelity or returning to spawn in the same nest site was only 
documented for this one female, and sequential polyandry was documented for the remaining 13 of 14 $(92.8 \%)$ multiple spawning females, who changed mates when spawning in later cycles.

Reconstructed female genotypes allowed us to document the number of female contributors to each male's nest. We documented males spawning with as few as four, to as many as 14 females over the 3.5 month period. Polygynous matings were detected in 54 of 68 nests $(79.4 \%)$; the remaining nests contained clutches that were not sampled or single clutches.

\section{Discussion}

Genetic evidence from offspring allows us to describe new aspects of reproductive behavior in A. sordidus at Johnston Atoll. Previous studies have observed that the same males return to defend their nest sites [25]. This study used genetic methods to confirm that males utilize the same nests over multiple nesting cycles but also documented that some males practice alternative reproductive tactics such as reproductive parasitism through sneaked fertilizations, which have not been observed or reported previously. Like previous studies, this study documented multiple clutches being deposited in a nest. However, the number of females spawning in a clutch and the population was not known. Here we provide genetic evidence as to the identity and number of females spawning within a clutch as well as multiple clutches within a nest, also over multiple reproductive cycles. Additionally, the use of female genotypes provided new evidence on female spawning frequency and behavior including serial polyandry.

\subsection{Mating System}

A promiscuous mating system in A. sordidus, a damselfish with male parental care, was defined using genetic data. Promiscuous mating systems in fishes are common [29], but the occurrence and genetic documentation of female multiple mating in species with male parental care varies $[6,19,20]$. This study found evidence of multiple matings for both sexes over several reproductive cycles. Males were polygynous within and between cycles, as compared to multiple mating females that were primarily monandrous within, but polyandrous between cycles, with 13 of 14 multiple mating females switching mates. While the data suggest that majority of females (60 of 74) only spawned once during the 3.5 month period, it cannot be ruled out that some of these females likely spawned elsewhere or remained unidentified in mixed or unsampled clutches. However, individuals that spawned only one time may also have been smaller females without sufficient body condition for spawning multiple times.

Uncertainty due to low numbers of offspring sampled per clutch and potential errors in maternal assignments resulted in low power for the detection of both multiple maternal contributors and parasitic males. While these results are consistent with spawning observations, they provide an initial, but likely lower end estimate for the occurrence of these behaviors.

\subsection{Male Reproductive Behavior}

Alternative reproductive tactics (ARTs) [30] occur when males attempt to steal fertilizations from other males monopolizing reproductive opportunities. In nest tending species, reproductive parasites exploit the investment of territory holders or "bourgeois" males who expend energy in obtaining and defending resources and offspring [31]. Parasitic spawning was not previously documented for this species. Such behavior benefits the "parasitic male" who gain fertilizations while not expending energy in caring for offspring or defending a territory. Our results showed that up to $14.7 \%$ of clutches contained offspring inconsistent with paternity by the territorial male indicating that the nest tending male participated in alloparental care. Two guardian males were identified as parasites spawning in other nests, suggesting that guardian males sneak fertilizations while their neighbors spawned. In both cases, the parasitic guardian male had not yet obtained a clutch but was present at his nest site. As the males were not guarding embryos, this allowed them to leave their nest and sneak fertilizations with a spawning neighbor. In the case of male F2, this neighbor was less than $2.5 \mathrm{~m}$ away within 
the same metal structure. While the sampling method covered large portions of a clutch and larval collection was essentially random within a large pool of larvae, the low numbers genotyped per clutch may underestimate the level of parasitism occurring. On the other hand, some mismatches may also have resulted from genotyping error, overestimating the occurrence of parasitic spawning. Future work, to determine precise levels of reproductive parasitism and the reproductive success of both parasitic and guardian males, should employ additional markers and analyses of larger numbers of offspring. Larger sample sizes might also resolve whether the single locus mismatches in some offspring were typing errors, or true mismatches due to parasitism. However, as a first estimate of the percentage of clutches parasitized, $14.7 \%$ is comparable to lower end estimates from other nest tending species $[19,32]$. If the additional nine clutches with single locus mismatches are included as incidences of parasitism, the estimate of clutches parasitized increases to $21.7 \%$. While it is significant that this study documented $A$. sordidus males practicing ARTs, the total effect on the reproductive success of the nest tender as well as the parasitic male was not quantifiable.

The genetic data indicate that parasitic $A$. sordidus males were successful at fertilizing eggs within territorial male's nests and that some of these males were identified as adjacent or nearby territory holders, but there were additional unidentified males (i.e., non-territory holders) who may have been unsuccessful in the competition for nest sites. These parasite-intruders might gain access to the nest through streaking (rapidly releasing gametes while rushing the spawning pair). In the damselfish Chromis chromis this occurs as many as 2.8 times per ten minutes during spawning [17], and cuckoldry was observed in every nest sampled [33]. Other tactics the parasite might employ to gain access to fertilizations include stealth in the form of drab coloration that is similar to female coloration [31]. Such deceit through female mimicry was also observed in male C. chromis [17]. The advantage of using these tactics is that the parasitic male gains fertilizations without the cost of defending a territory or providing parental care.

Consistent with spawning observations, our genetic evidence indicated that the majority of A. sordidus nests contained clutches spawned by a single female, but there is also genetic evidence that some clutches have multiple maternal contributors. Individual females spawned $76.7 \%$ of the individual clutches within a male's nest, with up to four additional clutches being spawned in the nest during the same spawning cycle. As spawning events lasted several hours and only one clutch was laid in a nest per day, sequential spawning with only one female may serve as an adaptation against female mimic sneaker males. For example, Stegastes nigricans will only spawn sequentially with females, chasing off a second female trying to enter the nest site [34]. However, evidence of multiple females contributing to a clutch, might suggest either a distraction or an opportunity for males to mimic females as a means to gain access to the nest.

Factors influencing the occurrence of male ARTs include female preference for nests that already contain eggs [35,36] spawning synchrony and nest density [37-40]. Nest "piracy" provides a method for males to take advantage of female's preference for nests containing embryos without expending energy on territory maintenance or courtship [41]. As there were no clutches where none of the offspring matched the guardian male, there was no evidence for nest takeovers.

A. sordidus are temporarily territorial pomacentrids with males present at their nest sites only during reproductive activities $[25,27]$. Spawning was not highly synchronized and nest densities were also low as compared to other temporarily territorial species [40]. Therefore intrusion rates may be reduced, as neighboring males may not be present during a given spawning bout, or are too far away, reducing the opportunities for reproductive parasitism $[17,38]$. However, males will take advantage of spawning neighbors, as there were two instances of territorial males being identified as parasitic males in their neighbors' nests. As many of the parasitic spawners were not identified, it is likely that the majority of stolen fertilizations were from smaller, non-territorial males who are unable to compete for nest sites [31,42].

Distribution of nesting resources and population size also influence mating systems. Competition for limited nest sites found primarily on man-made debris appears to result in increased mating 
opportunities for the males able to defend these sites. Reproductive output also varied between the guardian males suggesting factors beyond availability of nesting resources also influence reproductive success.

The group of males studied here was found in the largest aggregation or colony of $A$. sordidus within the atoll [27]. While surveys identified 40 nesting sites at this location, they were not used consistently every year or even every spawning cycle indicating the sites may vary in quality. Additional surveys around the island and other reef areas within the atoll, only found solitary individuals [27]. Study site surveys conducted during daily dives, observed very few (1-3 individuals) A. sordidus in the colony between reproductive cycles. Therefore it appears that the site functions primarily as a reproductive arena or aggregation site as opposed to permanent territories for the fish. The overall number of males competing for these sites is not known but the genetic analysis suggests a minimum of 36 reproductive parasites or sneaker males were detected in offspring samples. There were at minimum, 74 individual females spawning in the nest sites defended by these 10 guardian males. This female biased operational sex ratio (OSR) reflects resource competition for nesting sites among males, but may also suggest that mating competition could occur between females attempting to access limited oviposition sites [43]. The physical space needed for one clutch can be quite large, with the smallest clutch documented measuring $22 \times 30 \mathrm{~cm}$, so that multiple clutches require much more defendable space [27]. At Johnston, the availability of oviposition sites may influence female A. sordidus movements. As so few non-territory holding individuals were observed in the study site on a daily basis, it is possible that females migrated from other locations to find suitable mates and/or oviposition sites.

\subsection{Female Reproductive Behavior}

Spawning females left their entire clutch with one male during a single spawning bout, but some females were identified spawning in additional cycles. Two of the females spawned three times during the study. There were too few multiple spawning females to accurately determine the spawn interval, but the minimum time detected between two clutches spawned by one female was 14 days. Within-day polyandrous matings were not detected in A. sordidus. Within-day polyandrous matings do occur in other pomacentrids, accounting for $<6 \%, 0 \%$ to $1.2 \%, 2.9 \%$ to $4.1 \%$ and $<15 \%$ of all matings in Stegastes nigricans, S. dorsopunicans, Dascyllus aruanus, and Amblyglyphidodon leucogaster, respectively $[12,34,44,45]$. However, like $A$. sordidus, female Chromis notata generally mate with a single male per spawning day [46].

We documented sequential polyandry for $A$. sordidus females with 13 of the 14 multiple spawning females changing mates at least one time. Only one female spawned two times with the same male. Other pomacentrids including Stegastes nigricans, S. dorsopunicans, Dascyllus aruanus, and Amblyglyphidodon leucogaster also change their mates frequently over the season $[12,34,44,45]$. In contrast, female Stegastes partitus show high mate fidelity only changing mates due to nest loss or failure $[47,48]$. It is likely than many of the other females spawned multiple times in nests that were not sampled and that some may have contributed to the nests with multiple female contributors and were not detected due to small number of offspring sampled. To further understand female spawning behavior and frequency, it will require larger offspring samples collected from all nests. Determining if females migrate between spawning "aggregations" would also require additional sampling at these location.

Factors influencing female choice include male size [49], territory quality and defense [37,50], courtship rate/intensity [16], and the presence and survival of eggs [48,51,52]. Future analysis will examine the influence of nest density and spawning synchrony in the preference of female $A$. sordidus for some males (or the territories they were able to secure) over others, as evident through highly variable male reproductive success. Specifically, males receiving the highest number of clutches also appear to have more of the multiple spawning females returning to spawn within their nests. So, if some males were preferred over others due to better territories or better offspring care, why would multiple 
mating females choose to mate with other males? Genetic bet-hedging is a female strategy whereby having offspring sired by more than one male allows females to reduce errors made assessing mates under variable environmental conditions (genetic diversity hypothesis), or due to a females ability to discriminate between male genotypes (good genes hypothesis) [53]. Since female reproductive behaviors vary, ultimately influencing mating systems and male reproductive success, it is therefore important to consider both male and female reproductive ecology and their interactions in order to gain an understanding of the evolution of mating systems $[7,54]$.

\section{Materials and Methods}

\subsection{Nest Site Monitoring and Sample Collection}

The study site was located at Sand Island, one of the small islands within Johnston Atoll $\left(16^{\circ} 46^{\prime} \mathrm{N}\right.$, $169^{\circ} 30^{\prime} \mathrm{W}$; Figure 2 ). The nesting activity by $A$. sordidus in this study was monitored for 14 weeks at the west end of Sand Island in from 7 March to 23 June, 1998. Nest sites were identified through direct observations (while using scuba) of individual $A$. sordidus exhibiting territorial, nest tending or guarding behaviors. Individuals were observed for five minutes to determine if a particular area was (a) being defended, or (b) if the substrate was cleaned to receive embryos, or (c) if courtship coloration or courtship behavior was observed, and (d) if the individual was already defending embryos. Nest site locations were marked with flagging tape and inspected daily by the same scientific scuba diver (LKL). Spawning activity for each of these ten nest locations was documented by recording the date and location of clutches spawned in each nest. A clutch was defined as a continuous mass of embryos of the same developmental stage. A nest cycle included all clutches spawned within five days of each other, and lasted until the final clutch hatched (Figure 1).

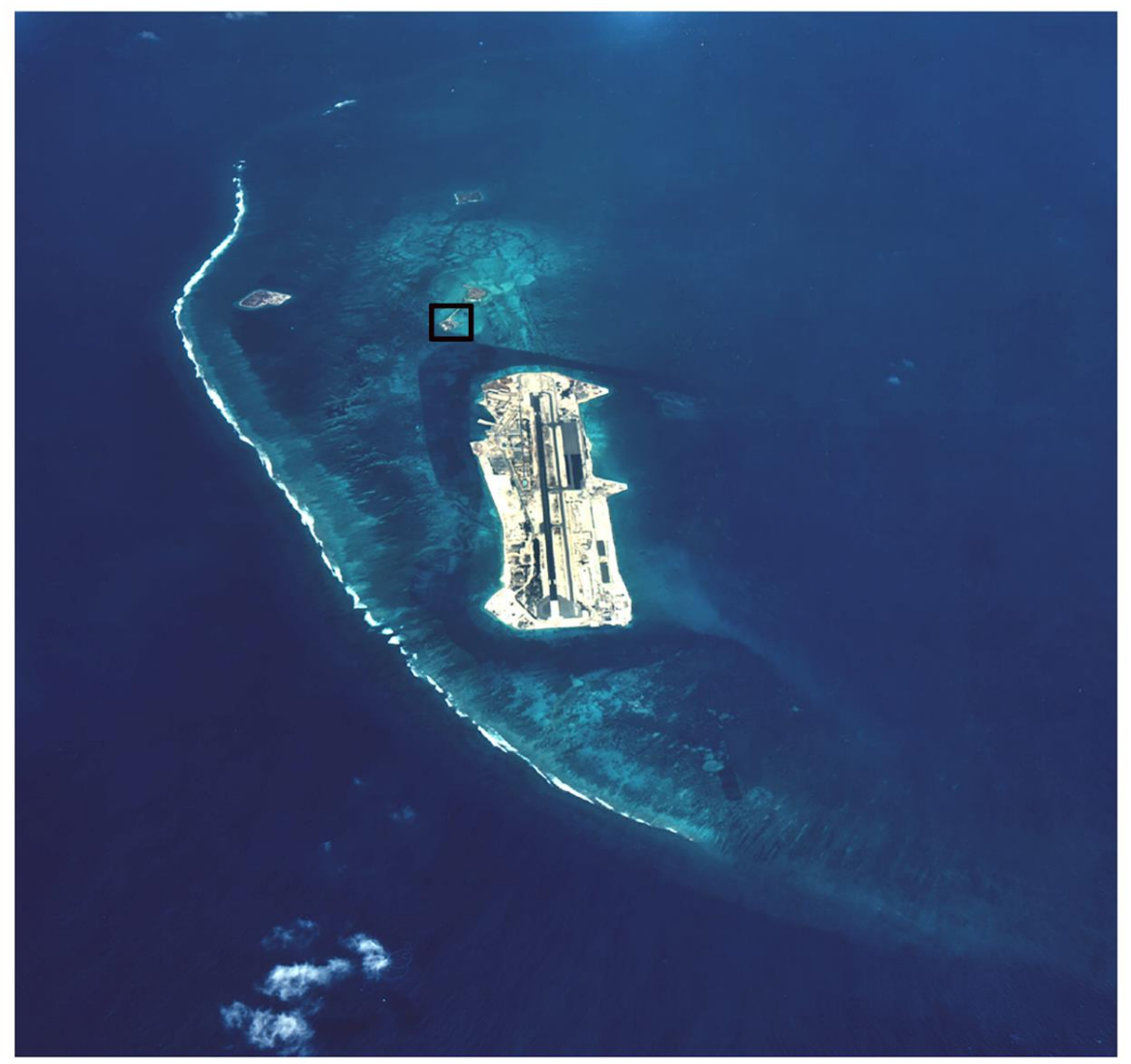

Figure 2. Aerial view of Johnston Atoll looking east. Johnston Island is the largest, with East Island the farthest to the east of Johnston, and North Island to the left or north of Johnston. The black box surrounds the study location at the west end of Sand Island. 
Fin clips were collected from ten A. sordidus adults by baiting fish into hand nets. Individual males defending nest sites were specifically targeted. The fish were released after fin clips were taken. Offspring samples were collected by scraping a sample of embryos (approximately 1000-2000) from across the entire diameter of the clutch into a labeled $50 \mathrm{~mL}$ sample tube. In the laboratory, embryos were placed in aerated $500 \mathrm{~mL}$ jars with fresh seawater and allowed to hatch. Approximately 25 offspring were randomly collected from the initial 1000-2000 sampled from each clutch and preserved in $95 \%$ ethanol. Spawning and embryo hatching was also observed in the field to confirm the end of each reproductive cycle for the 10 males. The work was performed under USFWS special use-permit 12515-00003 and MBL IACUC 97-04.

\subsection{Microsatellite Methods}

Genomic DNA from adult $A$. sordidus individuals was extracted using DNeasy Tissue Kit (QIAGEN) and sent to Genetic Identification Services (GIS; Chatsworth, CA, USA) to prepare enriched microsatellite libraries with ATG-, CATC-, and TAGA- repeats using standard procedures [55]. GIS identified and designed primers for 48 potential microsatellite loci. We initially screened 22 loci and optimized PCR conditions on 10 unrelated adults for six loci.

Ten individual offspring (larvae or embryo) from each clutch were haphazardly chosen and individually extracted. Larval head tissue was used for extraction, except for the few cases where larvae could not be collected, in which case the embryos were extracted after puncturing the chorion. Genotypes were successfully created for a mean of $8(S D=2.6)$ offspring per clutch. DNA was extracted in $225 \mu \mathrm{L}$ of $10 \%$ Chelex solution which was vortexed for $15 \mathrm{~s}$ and incubated at $95^{\circ} \mathrm{C}$ for $20 \mathrm{~min}$. Samples were vortexed then centrifuged for $15 \mathrm{~s}$ at 14,000 rpm. Offspring and the 10 adult tissue samples were genotyped at six microsatellite loci. DNA amplifications were performed in a 10- $\mu \mathrm{L}$ reaction volume containing $10 \mathrm{mM}$ Tris- $\mathrm{HCl}$ ( $\mathrm{pH} 8.3$ ), $50 \mathrm{mM} \mathrm{KCl}, 200 \mu \mathrm{M}$ of each dNTP, $2 \mathrm{mM} \mathrm{MgCl}$, $0.5 \mu \mathrm{M}$ of each primer, and 0.5 $\mathrm{U}$ of AmpliTaq (ABI). PCR was performed on an Whatman Biometra Tgradient 96 thermocycler (Biometra) with the cycling settings: 1 min melt at $94{ }^{\circ} \mathrm{C}$, followed by 30 cycles of $94^{\circ} \mathrm{C}$ for $1 \mathrm{~min}, 56^{\circ} \mathrm{C}$ for $30 \mathrm{~s}$, and $72^{\circ} \mathrm{C}$ for $30 \mathrm{~s}$, followed by a final extension at 72 for $5 \mathrm{~min}$. PCR Primers were end-labeled with different fluorescent dyes (HEX or 6-FAM) and PCR products from two loci (D123 and D113; D112 and D7; C9 and D102) were combined with $0.25 \mu \mathrm{L}$ of ROX size standard MRK400 in $2.75 \mu \mathrm{L}$ of 377 loading solution. Samples were denatured at $94{ }^{\circ} \mathrm{C}$ for three min, quenched, then $1 \mu \mathrm{L}$ of duplexed sample was loaded onto paper combs and electrophoresed using an ABI PRISM ${ }^{\circledR} 377$ Automated DNA Sequencer. Alleles were sized with respect to electrophoretic mobility using Genescan (ABI) and STRand software packages (http://www.vgl.ucdavis.edu/STRand, version 2.2.30).

Allele frequency analysis included: observed and expected heterozygosity, polymorphic information content (PIC), goodness-of-fit Hardy-Weinberg equilibrium tests, null allele frequency (based on heterozygote deficit) and average non-exclusion probabilities (Cervus 3.0.7).

\subsection{Genetic Parentage}

To determine parentage, multilocus genotypes from offspring samples, grouped by clutch, were screened for mismatches with guardian male genotype. Each of the genotypes from the 10 guardian males was obtained from a tissue sample. A mismatch at a single locus within a single offspring was considered to be a scoring or other type of error, in which case the guardian male was considered to be the father. However, in cases where offspring had mismatched paternal alleles at two or more loci, these genotypes were considered to be inconsistent with paternity by the guardian male. Colony v. 2.0.6.5 (https://www.zsl.org/science/software/colony) was used to verify paternity assignments in clutches with mismatched loci, to determine the number of paternal contributors to these clutches and to provide sneaker male genotypes.

Maternal genotypes were identified from presumed full or half sib offspring arrays (clutches) using GERUD v. 2.0 (https://github.com/JonesLabTAMU/Gerud2) and the known paternal genotype from 
male tissue samples [56,57]. However, if paternal mismatches occurred or other evidence that more than two individuals contributed to a clutch (e.g., more than two paternal or two maternal alleles at each locus), multilocus maternal genotypes could not be identified for that clutch. Maternal genotypes were identified in some clutches containing mismatches after removing the offspring with the mismatches from the array. GERUD provided an estimate of the minimum number of females contributing to the clutch based on the number of maternal alleles in the progeny sample. A single mother was indicated if no more than two maternal alleles were present at each locus in all assayed offspring. Female genotypes identified in these clutches with only one maternal contributor were used to determine (a) if female multiple spawnings could be detected, and (b) if females displayed nest site fidelity, and (c) if polyandrous spawnings occurred within the territories of the ten guardian males.

\section{Conclusions}

This study used genetic data collected from guardian males and offspring to interpret and provide an initial estimate for $A$. sordidus reproductive behaviors and parameters including: (1) The frequency and number of females spawning in the territories of ten males, where a total of 94 female $A$. sordidus spawned one to four times; (2) Sequential polyandry, where 13 of 14 multiple mating females switched mates at least once during sequential reproductive cycles; (3) Males exhibited high nest site fidelity; (4) Polygyny, males cared for broods with one to four clutches spawned by different females per reproductive cycle; (5) Variable male reproductive success with males caring for four to 19 clutches spawned by up to 14 different females in up to nine reproductive cycles; as well as (6) The occurrence of reproductive parasitism where offspring genotypes were inconsistent with paternity by the guardian male in up to $14.7 \%$ of clutches analyzed. These data corroborated several findings, as well as adding to the known reproductive tactics of this and other pomacentrids, demonstrating that genetic data can be useful in elucidating reproductive behaviors in natural populations where reproductive behaviors are difficult to observe directly and the presence or success of alternative reproductive tactics are unknown.

Supplementary Materials: The following are available online at http://www.mdpi.com/2410-3888/4/4/53/s1, Table S1: Genotype data at six microsatellite loci for guardian males, maternal contributors (reconstructed) and offspring grouped by clutch; Video S1: Abudefduf sordidus spawning.

Author Contributions: Individual authors contributed as follows: conceptualization, L.K.L.; study design L.K.L., P.S.L.; underwater data collection L.K.L., P.S.L.; DNA methodology and analysis, L.K.L., D.M.D.; resources, P.H.B. and P.S.L.; data curation, D.M.D. and L.K.L.; writing - original draft preparation, L.K.L.; writing一review and editing, L.K.L., D.M.D., and P.S.L.; visualization, L.K.L.; project administration, P.S.L., P.H.B.; funding acquisition, P.S.L.

Funding: This work was supported by grants provided by the Army Research Office (DAAG55-98-1-0304, DAAD19-02-1-0218), Office of Naval Research (N00014-19-J1519, N00014-92-J-1969 and N00014-95-1-1324), and Legacy Resource Management Program (DADA87-00-H-0021, DACA87-01-H-0013).

Acknowledgments: Our study was part of the US Army's Johnston Atoll chemical weapons demilitarization program and was sponsored to implement coral reef conservation and protection. We owe our many friends and colleagues at DoD as well as our scientific partners huge thanks for making our research in the Pacific Islands possible.

Conflicts of Interest: The authors declare no conflict of interest. The funders had no role in the design of the study; in the collection, analyses, or interpretation of data; in the writing of the manuscript, or in the decision to publish the results.

\section{References}

1. Andersson, M. Evolution of classical polyandry: Three steps to female emancipation. Ethology 2005, 111, 1-23. [CrossRef]

2. Shuster, S.M.; Briggs, W.R.; Dennis, P.A. How multiple mating by females affects sexual selection. Philos. Trans. R. Soc. B 2013, 368, 20120046. [CrossRef] [PubMed]

3. Berglund, A. Mating systems and sex allocation. In Behavioural Ecology of Teleost Fishes; Godin, J.J., Ed.; Oxford University Press: Oxford, UK, 1997; pp. 237-259. 
4. Emlen, S.T.; Oring, L.W. Ecology, sexual selection, and the evolution of mating systems. Science 1977, 197, 215-223. [CrossRef] [PubMed]

5. Rios-Cardenas, O.; Morris, M.R. Mating systems and strategies of tropical fishes. In Tropical Biology and Conservation Management_-Volume VIII: Zoology; del Claro, K., Oliveira, P.S., Rico-Gray, V., Eds.; EOLSS Publishers: Oxford, UK, 2009; pp. 219-240.

6. King, J.R.; Withler, R.E. Male nest site fidelity and female serial polyandry in lingcod (Ophiodon elongatus: Hexagrammidae). Mol. Ecol. 2005, 14, 653-660. [CrossRef] [PubMed]

7. Henson, S.A.; Warner, R.R. Male and female alternative reproductive behaviors in fishes: A new approach using intersexual dynamics. Ann. Rev. Ecol. Syst. 1997, 28, 571-592. [CrossRef]

8. Thresher, R.E. Reproduction in Reef Fishes; TFH Publications: Neptune City, NJ, USA, 1984.

9. Petersen, C.W. Male mating success and female choice in permanently territorial damselfishes. Bull. Mar. Sci. 1995, 57, 690-704.

10. Knapp, R.A.; Kovach, J.T. Courtship as an honest indicator of male parental quality in the bicolor damselfish, Stegastes partitus. Behav. Ecol. 1991, 2, 295-300. [CrossRef]

11. Horne, E.A.; Itzkowitz, M. Behaviour of the female beaugregory damselish (Stegastes leucosticus). J. Fish Biol. 1995, 46, 457-461. [CrossRef]

12. Goulet, D. Reproductive behavior and spawning success of female Amblyglyphidodon leucogaster (Pisces: Pomacentridae) from the Red Sea. Environ. Biol. Fishes 1997, 50, 49-60. [CrossRef]

13. Karino, K.; Kuwamura, T. Plasticity in spawning visits of female damselfish, Stegastes nigricans: Effect of distance to mates. Behav. Ecol. Sociobiol. 1997, 41, 55-59. [CrossRef]

14. Sikkel, P.C. Factors influencing spawning site choice by female Garibaldi, Hypsypops rubicundus (Pisces: Pomacentridae). Copeia 1998, 3, 710-718. [CrossRef]

15. Itzkowitz, M.; Draud, M.J.; Triefenback, R.; Haley, M. The mating pattern of females when territorial differences among males are reduced: A test in the polygynous beaugregory damselfish. Behavior 2001, 138, 691-708.

16. Oliver, S.J.; Lobel, P.S. Direct mate choice for simultaneous acoustic and visual displays in the damselfish, Dascylllus albisella (Pomacentridae). Environ. Biol. Fishes 2013. [CrossRef]

17. Picciulin, M.; Verginella, L.; Spoto, M.; Ferrero, E.A. Colonial nesting and the importance of brood size in male parasitic reproduction of the Mediterranean damselfish Chromis chromis. Environ. Biol. Fishes 2004, 70, $23-30$. [CrossRef]

18. DeWoody, J.A.; Avise, J.C. Genetic perspectives on the natural history of fish mating systems. J. Hered. 2001, 92, 167-172. [CrossRef] [PubMed]

19. Avise, J.C.; Jones, A.G.; Walker, D.; DeWoody, J.A. Genetic mating systems and reproductive natural histories of fishes: Lessons for ecology and evolution. Ann. Rev. Genet. 2002, 36, 19-45. [CrossRef]

20. Coleman, S.W.; Jones, A.G. Patterns of multiple paternity and maternity in fishes. Biol. J. Linn. Soc. 2011, 103, 735-760. [CrossRef]

21. Froese, R.; Pauly, D. (Eds.) FishBase 2000: Concepts, Design and Data Sources; ICLARM: Los Baños, CA, USA; Laguna, Philippines, 2000; Available online: http://www.fishbase.org/home.htm (accessed on 15 October 2019).

22. Breder, C.M.; Rosen, D.E. Modes of Reproduction in Fishes; Natural History Press: Garden City, NY, USA, 1966.

23. Allen, G.R. Damselfishes of the World; Mergus publishers: Melle, Germany, 1991.

24. Myers, R.F. Micronesian Reef Fishes: A Comprehensive Guide to the Coral Reef Fishes of Micronesia, 3rd ed.; Coral Graphics: Barrigada, Guam, USA, 1999; Volume 297.

25. Stanton, F.G. Temporal patterns of spawning in the demersal brooding blackspot sergeant Abudefduf sordidus (Pisces: Pomacentridae) from Kaneohe Bay (Hawaii). In Proceedings of the 8th International Coral Reef Congress, Tahiti, French Polynesia, 27 May-1 June 1985; Volume 5, pp. 361-366.

26. Lobel, P.S.; Kerr, L.M. Courtship sounds of the Pacific damselfish, Abudefduf sordidus (Pomacentridae). Biol. Bull. 1999, 197, 242-244. [CrossRef]

27. Lobel, L.K.; Lobel, P.S. Junkyard damselfishes: Spawning behavior and nest site selection. In Diving for Science, Proceedings of the American Academy of Underwater Sciences/European Scientific Diving Panel Joint International Scientific Diving Symposium; Lang, M., Sayer, M., Eds.; American Academy of Underwater Sciences: Curaçao, Netherlands Antilles, 2013; pp. 167-178.

28. Kerr, L.M. Developmental defects in damselfish (Abudefduf sordidus, Pomacentridae) embryos from metal artificial reefs. Biol. Bull. 1996, 191, 306-307. [CrossRef] 
29. Taylor, M.I.; Knight, M.E. Mating systems in fishes. In Fish Reproduction; Rocha, M.J., Arukwe, A., Kapoor, B.G., Eds.; CRC Press: Boca Raton, FL, USA, 2008; pp. 277-309.

30. Taborsky, M. The evolution of bourgeois, parasitic and cooperative mating behaviors in fishes. J. Hered. 2001, 92, 100-110. [CrossRef]

31. Taborsky, M. Sneakers, satellite and helpers: Parasitic and cooperative behaviour in fish reproduction. Adv. Study Behav. 1994, 23, e100.

32. Mackiewicz, M.; Porter, B.A.; Dakin, E.E.; Avise, J.C. Cuckoldry rates in the molly miller (Scrartella cristata; Blenniidae), a hole-nesting marine fish with alternative reproductive tactics. Mar. Biol. 2005, 148, $213-221$. [CrossRef]

33. Mascolino, S.; Benvenuto, C.; Gubili, C.; Sacchi, C.; Boufana, B.; Mariani, S. The ART of mating: Alternative reproductive tactics and mating success in a nest-guarding fish. J. Fish Biol. 2016, 89, 2643-2657. [CrossRef] [PubMed]

34. Karino, K.; Nakazono, A. Reproductive behaviour of territorial herbivore Stegastes nigricans (Pisces: Pomacentridae) in relation to colony formation. J. Ethol. 1993, 11, 99-110. [CrossRef]

35. Goulet, D. Spawning success in the damselfish Amblyglyphidodon leucogaster: The influence of eggs in the nest. Anim. Behav. 1998, 55, 651-664. [CrossRef]

36. Unger, L.M.; Sargent, R.C. Allopaternal care in the fathead minnow, Pimephales promelas: Females prefer males with eggs. Behav. Ecol. Sociobiol. 1988, 23, 27-32. [CrossRef]

37. Goldschmidt, T.; Foster, S.A.; Sevenster, P. Inter-nest distance and sneaking in the three-spined stickleback. Anim. Behav. 1992, 44, 793-795. [CrossRef]

38. Tyler, W.A. The adaptive significance of colonial nesting in a coral-reef fish. Anim. Behav. 1995, 49, 949-966. [CrossRef]

39. Mackiewicz, M.; Fletcher, D.E.; Wilkins, D.; DeWoody, J.A.; Avise, J.C. A genetic assessment of parentage in a natural population of dollar sunfish (Lepomis marginatus) based on microsatellite markers. Mol. Ecol. 2002, 11, 1877-1883. [CrossRef]

40. Barnett, C.W.; Pankhurst, N.W. Effect of density on the reproductive behaviour of the territorial male demoiselle Chromis dispilus (Pisces: Pomacentridae). Environ. Biol. Fishes 1996, 46, 343-349. [CrossRef]

41. Taborsky, M.; Hudde, B.; Wirtz, P. Reproductive behaviour and ecology of Symphodus (Crenilabrus) ocellatus, a European wrasse with four types of male behaviour. Behaviour 1987, 102, 82-118. [CrossRef]

42. Taborsky, M. Sperm competition in fish: 'Bourgeois' males and parasitic spawning. Trends Ecol. Evol. 1998, 13, 222-227. [CrossRef]

43. Ahnesjö, I.; Kvarnemo, C.; Merilaita, S. Using potential reproductive rates to predict mating competition among individuals qualified to mate. Behav. Ecol. 2001, 12, 397-401. [CrossRef]

44. Asoh, K. Reproductive parameters of female Hawaiian damselfish Dascyllus albisella with comparison to other tropical and subtropical damselfishes. Mar. Biol. 2003, 143, 803-810. [CrossRef]

45. Petersen, C.W.; Hess, H.C. The adaptive significance of spawning synchronization in the Caribbean damselish Stegastes dorsopunicans (Poey). J. Exp. Mar. Biol. Ecol. 1991, 151, 155-167. [CrossRef]

46. Ochi, H. Termination of parental care due to small clutch size in the temperate damselish, Chromis notata. Environ. Biol. Fishes 1985, 12, 155-160. [CrossRef]

47. Knapp, R.A.; Warner, R.R. Male parental care and female choice in the bicolor damselfish, Stegastes partitus: Bigger is not always better. Anim. Behav. 1991, 41, 747-756. [CrossRef]

48. Knapp, R.A. The influence of egg survivorship on the subsequent nest fidelity of female bicolour damselfish, Stegastes partitus. Anim. Behav. 1993, 46, 111-121. [CrossRef]

49. Lindström, K. The evolution of filial cannibalism and female mate choice strategies as resolutions to sexual conflict. Evolution 2000, 54, 617-627. [CrossRef]

50. Sikkel, P.C. Effects of nest quality on male courtship and female spawning site choice in an algal-nesting damselfish. Bull. Mar. Sci. 1995, 57, 682-689.

51. Kraak, S.B.M.; van den Berghe, E.P. Do female fish assess paternal quality by means of test eggs? Anim. Behav. 1992, 43, 865-867. [CrossRef]

52. Kraak, S.B.M.; Groothius, T.G.G. Female preference for nests with eggs is based on the presence of the eggs themselves. Behaviour 1994, 131, 189-206.

53. Yasui, Y. Female multiple mating as a genetic bet-hedging strategy when mate choice criteria are unreliable. Ecol. Res. 2001, 16, 605-616. [CrossRef] 
54. Kvarnemo, C.; Simmons, L.W. Polyandry as a mediator of sexual selection before and after mating. Philos. Trans. R. Soc. B 2013, 368, 20120042. [CrossRef] [PubMed]

55. Glenn, T.C.; Schable, N.A. Isolating microsatellite DNA loci. Methods Enzymol. 2005, 395, 202-222.

56. Jones, A. Gerud 2.0: A computer program for the reconstruction of parental genotypes from half-sib progeny arrays with known or unknown parents. Mol. Ecol. 2005, 5, 708-711. [CrossRef]

57. Parker, A.; Kornfield, I. Polygynandry in Pseudotropheus zebra, a cichlid fish from Lake Malawi. Environ. Biol. Fishes 1996, 47, 345-352. [CrossRef]

(C) 2019 by the authors. Licensee MDPI, Basel, Switzerland. This article is an open access article distributed under the terms and conditions of the Creative Commons Attribution (CC BY) license (http://creativecommons.org/licenses/by/4.0/). 